\title{
Evaluation of Two Potent and Selective PET Radioligands to Image COX-1 and COX-2 in Rhesus Monkeys
}

\author{
Min-Jeong Kim, Stal S. Shrestha, Michelle Cortes, Prachi Singh, Cheryl Morse, Jeih-San Liow, Robert L. Gladding, \\ Chad Brouwer, Katharine Henry, Evan Gallagher, George L. Tye, Sami S. Zoghbi, Masahiro Fujita, Victor W. Pike, \\ and Robert B. Innis
}

Molecular Imaging Branch, National Institute of Mental Health, National Institutes of Health, Bethesda, Maryland

\begin{abstract}
This study assessed whether the newly developed PET radioligands ${ }^{11} \mathrm{C}-\mathrm{PS} 13$ and ${ }^{11} \mathrm{C}-\mathrm{MC} 1$ could image constitutive levels of cyclooxygenase (COX)-1 and COX-2, respectively, in rhesus monkeys. Methods: After intravenous injection of either radioligand, 24 whole-body PET scans were performed. To measure enzyme-specific uptake, scans of the 2 radioligands were also performed after administration of a nonradioactive drug preferential for either COX-1 or COX-2. Concurrent venous samples were obtained to measure parent radioligand concentrations. SUVs were calculated from 10 to 90 min. Results: ${ }^{11} \mathrm{C}-\mathrm{PS} 13$ showed specific uptake in most organs, including spleen, gastrointestinal tract, kidneys, and brain, which was blocked by COX-1, but not COX-2, preferential inhibitors. Specific uptake of ${ }^{11} \mathrm{C}-\mathrm{MC} 1$ was not observed in any organ except the ovaries and possibly kidneys. Conclusion: The findings suggest that ${ }^{11} \mathrm{C}-\mathrm{PS} 13$ has adequate signal in monkeys to justify its extension to human subjects. In contrast, ${ }^{11} \mathrm{C}-\mathrm{MC} 1$ is unlikely to show significant signal in healthy humans, though it may be able to do so in inflammatory conditions.
\end{abstract}

Key Words: cyclooxygenase-1; cyclooxygenase-2; positron-emission tomography; inflammation; nonsteroidal antiinflammatory agents

J Nucl Med 2018; 59:1907-1912

DOI: 10.2967/jnumed.118.211144

C yclooxygenase (COX) enzymes perform the rate-limiting step in the synthesis of inflammatory mediators such as prostaglandins and thromboxanes from arachidonic acid. The 2 primary isoforms, COX-1 and COX-2, are present constitutively, but only COX-2 shows marked upregulation in response to inflammation (1). For example, proinflammatory cytokines increased the expression of COX-2, but not COX-1, in synovial tissues from patients with rheumatoid arthritis (2). Nonsteroidal antiinflammatory drugs (NSAIDs) inhibit COX-1 or COX-2, but their major therapeutic effect is mediated by COX-2 inhibition. COX-1 inhibition, in turn, irritates the gastrointestinal tract. Thus, selective COX-2 inhibitors were developed in the 1990s to treat inflammatory disorders such as arthritis and pain, and to avoid gastrointestinal irritation.

The relative ability of NSAIDs to inhibit COX-1 versus COX-2 has been measured in vitro, but the effectiveness of NSAIDs in

\footnotetext{
Received Mar. 7, 2018; revision accepted Jun. 1, 2018.

For correspondence or reprints contact: Min-Jeong Kim, Molecular Imaging Branch, National Institute of Mental Health, 10 Center Dr., Bldg. 10, Room B1D43, Bethesda, MD 20892.

E-mail: min-jeong.kim@nih.gov

Published online Jun. 29, 2018.

COPYRIGHT (C 2018 by the Society of Nuclear Medicine and Molecular Imaging.
}

vivo is largely unknown, especially in the brain. For instance, some NSAIDs have active metabolites, so that the cumulative in vivo blockade is greater than that from the parent drug alone (3). In addition, the blood-brain barrier can differentially block entry of NSAIDs into the brain and confound the interpretation of clinical trials, a finding underscored by the conflicting results obtained by several relatively large trials of $2 \mathrm{COX}-2$-selective inhibitors, celecoxib and rofecoxib, to treat neuroinflammation in Alzheimer disease (4-6). In those trials, celecoxib had no effect, whereas rofecoxib was found to accelerate disease progression. However, after study completion, Dembo et al. reported that celecoxib concentrations in human cerebrospinal fluid were quite low, perhaps lower than those needed for therapeutic efficacy; in contrast, rofecoxib had excellent penetration of the blood-brain barrier (7). At the time that the clinical trials were conducted, little attention was paid to the concept of measuring target engagement so that results could be more clearly interpreted.

In this context, PET radioligands for COX-1 and COX-2 would allow the relative occupancy induced by the parent drug and any active metabolites to be measured in brain and other organs. However, to date, developing PET radioligands for COX-1 and COX-2 has had limited success. Shukuri et al. studied ${ }^{11} \mathrm{C}-$ ketoprofen methyl ester, which has 62 -fold higher selectivity for COX1 than for COX-2, in rodents and humans (8-10); however, this agent is confounded by quantitation issues for the radiolabeled prodrugs, making it difficult to distinguish whether radioactivity is retained in brain because of high-affinity binding to COX-1 or merely by trapping of the negatively charged acid. With regard to PET radioligands for COX-2, no results have been published from human or nonhuman primates, although a few candidate radioligands have been studied in rodent inflammation models (11-13).

Toward this end, our laboratory recently developed 2 PET radioligands, ${ }^{11} \mathrm{C}-\mathrm{PS} 13\left({ }^{11} \mathrm{C}-1,5-\right.$ bis-(4-methoxyphenyl)-3-(2,2,2-trifluoroethoxy)-1H-1,2,4-triazole) and ${ }^{11} \mathrm{C}-\mathrm{MC} 1{ }^{11} \mathrm{C}-6$-methoxy-2(4-(methylsulfonyl)phenyl)- $N$-(thiophen-2-ylmethyl)pyrimidin-4-amine), which are potent and selective for COX-1 and COX-2, respectively (Fig. 1) (14-16). Standard enzymatic assays using fresh whole blood from monkeys and humans demonstrated that both have high potency (half-maximal inhibitory concentration, $1 \mathrm{nM}$ ) to inhibit their cognate enzymes, and panel assays for a wide range of potential off-site targets also verified their high specificity to COX (15). Of note, both radioligands directly inhibit the target enzymes and are not prodrugs.

This study sought to determine whether ${ }^{11} \mathrm{C}-\mathrm{PS} 13$ and ${ }^{11} \mathrm{C}-\mathrm{MC} 1$ could be used to image constitutive levels of COX-1 and COX-2, respectively, in rhesus monkeys. Whole-body imaging was used to quantify uptake in both brain and peripheral organs. In vivo PET 


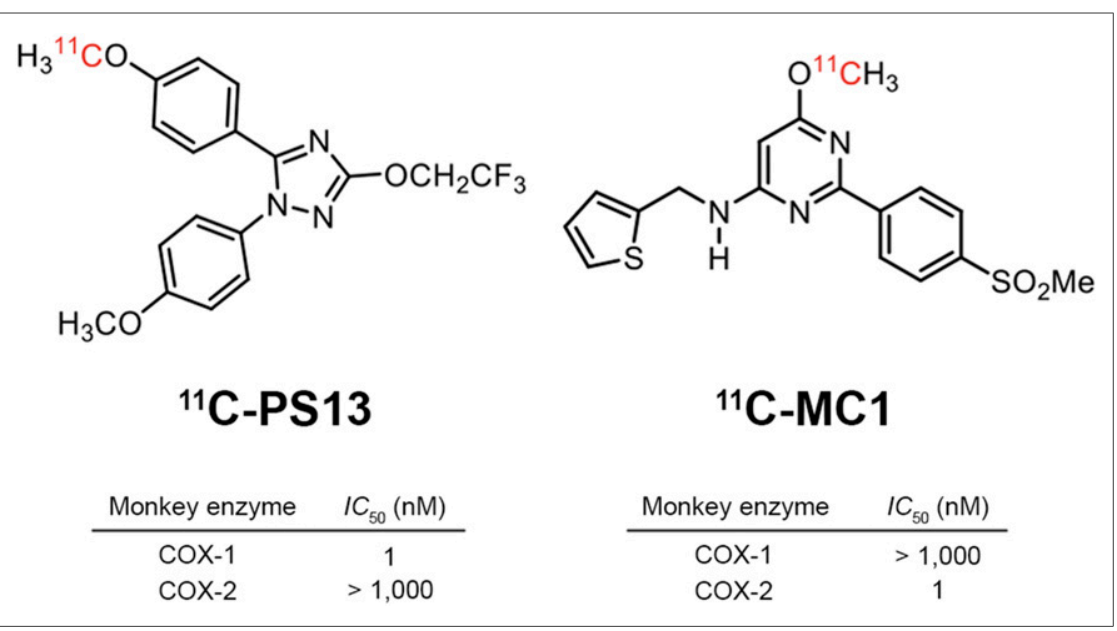

FIGURE 1. Chemical structures and in vitro potencies of PS13 and MC1 to inhibit COX-1 and COX-2, respectively, in fresh whole blood of rhesus monkeys (14-16). Almost identical potencies were found in human blood. $I C_{50}=$ half-maximal inhibitory concentration.

results were compared with the known distribution of these 2 enzymes, and the pharmacologic selectivity of each radioligand was assessed by blocking with subtype-selective drugs. The overarching goal of the study was to gather enough information to decide whether these 2 radioligands had adequate signal to extend to studies of human subjects.

\section{MATERIALS AND METHODS}

\section{Radiopharmaceutical Preparation}

${ }^{11} \mathrm{C}-\mathrm{PS} 13$ and ${ }^{11} \mathrm{C}-\mathrm{MC} 1$ were prepared as previously described (1416), with a molar activity of $128 \pm 43 \mathrm{GBq} / \mu \mathrm{mol}$ and $162 \pm 52 \mathrm{GBq} /$ $\mu \mathrm{mol}$, respectively, at the time of injection. Radiochemical purity was $99.9 \% \pm 0.1 \%$ for ${ }^{11} \mathrm{C}-\mathrm{PS} 13$ and $99.5 \% \pm 0.4 \%$ for ${ }^{11} \mathrm{C}-\mathrm{MC} 1$.

\section{Animals}

In vivo experiments were performed in 9 rhesus monkeys ( 1 female, 8 male; Macaca mulatta; 7.7-12.7 kg), most of whom underwent PET scans more than once. Monkeys were initially sedated via ketamine injection $(10 \mathrm{mg} / \mathrm{kg}$, intramuscularly) and then intubated. Anesthesia was maintained with $1.6 \%$ isoflurane and $98.4 \% \mathrm{O}_{2}$ for the duration of the study. The head was firmly fixed by gauze and tapes to the camera bed holder. Body temperature was maintained with heating pads, and temperature, oxygen saturation, blood pressure, and end-tidal $\mathrm{CO}_{2}$ were monitored for the duration of the study.

All animal studies were conducted in compliance with the Guide for the Care and Use of Laboratory Animals (17) and were approved by the National Institute of Mental Health Animal Care and Use Committee.

\section{Preparation of COX-1 and COX-2 Inhibitors as Preblockers}

In the preblockade study, PS13, ketoprofen, and aspirin (acetylsalicylic acid) were used as selective or preferential COX-1 inhibitors, and $\mathrm{MC} 1$ and celecoxib were used as selective COX-2 inhibitors.

\section{Scan Procedures}

Whole-body PET scans in monkeys were obtained on a Biograph mCT (Siemens Healthineers) scanner in 3 dimensions; transmission data for attenuation correction were acquired in 2 dimensions before radioligand injection. Dynamic emission scans in 4 different bed positions were obtained for 70-90 min in 18-20 frames after a 1-min intravenous bolus injection of the respective PET radioligand (222 $\pm 32 \mathrm{MBq}$ of ${ }^{11} \mathrm{C}-\mathrm{PS} 13$ and $205 \pm 26 \mathrm{MBq}$ of $\left.{ }^{11} \mathrm{C}-\mathrm{MC} 1\right)$. The injected mass dose was $0.21 \pm$ $0.09 \mathrm{nmol} / \mathrm{kg}$ for ${ }^{11} \mathrm{C}-\mathrm{PS} 13$ and $0.21 \pm 0.18$ $\mathrm{nmol} / \mathrm{kg}$ for ${ }^{11} \mathrm{C}-\mathrm{MC} 1$. To determine radioligand plasma concentrations, venous samples (2.0-3.0 mL each) were drawn from the saphenous vein at about 10,30,60, and $90 \mathrm{~min}$ after radioligand injection. Preblocking agent was intravenously administered $5-10 \mathrm{~min}$ before the radioligand in a preblocking study. PET images were reconstructed with filtered backprojection.

\section{Measuring ${ }^{11} \mathrm{C}-\mathrm{PS} 13$ and ${ }^{11} \mathrm{C}-\mathrm{MC} 1$ in Blood}

In each venous sample obtained from monkeys during the PET scans, the concentration of parent radioligand was measured after separating plasma from whole blood, as previously described (18).

\section{Image Processing and Analysis}

Whole-body PET images were calibrated to $\mathrm{Bq} / \mathrm{mL}$ and analyzed using PMOD, version 3.7 (PMOD Technologies Ltd., Zurich, Switzerland). Based on anatomic information from the corresponding CT scan, volumes of interest were delineated on major organs, and the time-activity curves were obtained. The activity of each organ was expressed as SUV. To quantify uptake, the average concentration of radioactivity in each organ was calculated from 10 to $90 \mathrm{~min}$. The first $10 \mathrm{~min}$, which are highly influenced by drug delivery and blood volume, were avoided. SUV was corrected for the average plasma concentration of radioligand measured at 4 timepoints to correct for any influence of the blocking drugs on metabolism and clearance of the radioligand. The effect of this plasma correction was also examined for each condition. Thus, the percentage blockade was calculated as [(baseline $\mathrm{SUV}_{10-90}$ min - preblocked $\left.\mathrm{SUV}_{10-90 \mathrm{~min}}\right) / \mathrm{base}$ line $\mathrm{SUV}_{10-90 \min } \times 100(\%)$ ], where $\mathrm{SUV}_{10-90}$ min means tissue to plasma ratio of SUV averaged from 10 to $90 \mathrm{~min}$.

\section{RESULTS}

\section{Pharmacologic Effects}

Injection of ${ }^{11} \mathrm{C}-\mathrm{PS} 13$ or ${ }^{11} \mathrm{C}-\mathrm{MC} 1$ had no pharmacologic effect at the radiotracer level on any animal, as assessed by the absence of significant changes in vital signs or electrocardiograms.

\section{COX-1 Radioligand: ${ }^{11} \mathrm{C}-\mathrm{PS} 13$}

Whole-Body Biodistribution and Specific Binding. In monkey, high uptake of ${ }^{11} \mathrm{C}$-PS13 was observed in major organs, including the brain, spleen, gastrointestinal tract, and kidneys. Uptake was blocked up to $92 \%$ by PS13 (Fig. 2 and Table 1). Although the bone marrow, liver, gallbladder, and urinary bladder also showed high ${ }^{11} \mathrm{C}$-PS13 uptake under baseline conditions, none of these were blocked by PS13. Other major organs such as the lungs and heart showed relatively low baseline uptake, and their percentage blockade varied. Plasma concentrations of ${ }^{11} \mathrm{C}$-PS13 were slightly increased up to $13 \%$ after administration of PS13 as a preblocker (Supplemental Fig. 1; supplemental materials are available at http://jnm.snmjournals.org), but percentage blockade in most organs did not significantly change regardless of whether plasma concentration correction was applied.

Selective Binding to COX-1. To evaluate the selective binding of ${ }^{11} \mathrm{C}-\mathrm{PS} 13$ to COX-1, ketoprofen $(3.0 \mathrm{mg} / \mathrm{kg})$ and aspirin $(11.1-$ $22.2 \mathrm{mg} / \mathrm{kg}$ ) were used as a selective and a preferential COX-1 


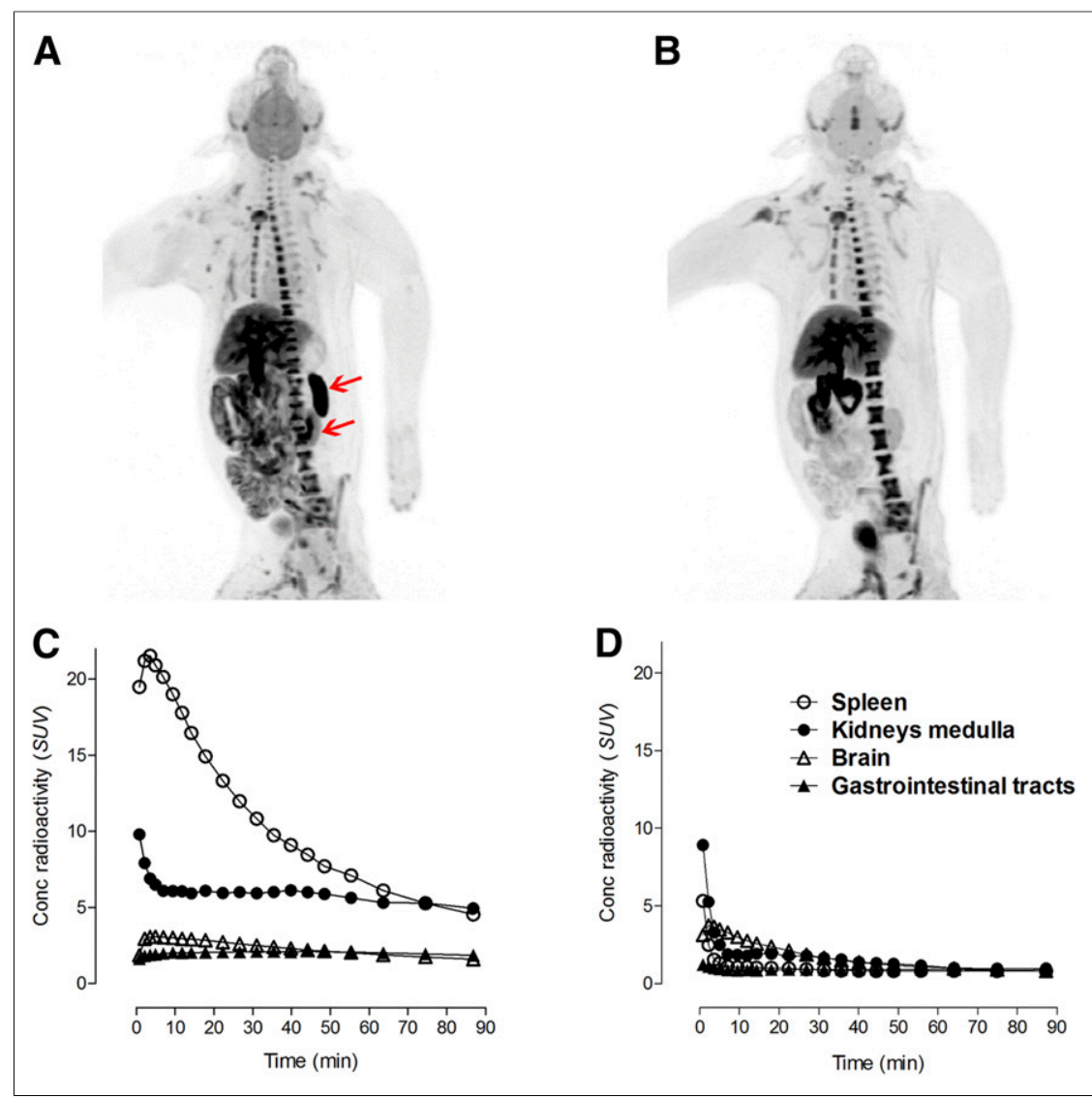

FIGURE 2. (A and B) Maximum-intensity projections after injection of ${ }^{11} \mathrm{C}-\mathrm{PS} 13$ under baseline conditions (A) and after injection of PS13 $(0.3 \mathrm{mg} / \mathrm{kg})(B)$. (C and D) Time-activity curves under baseline conditions (C) and after injection of PS13 $(1.0 \mathrm{mg} / \mathrm{kg})(\mathrm{D})$. High uptake was observed in brain, spleen, gastrointestinal tract, and kidney medulla at baseline. Uptake was blocked by pharmacologic doses of PS13. Upper arrow = spleen; lower arrow = left kidney; Conc $=$ concentration.

inhibitor, respectively, and $\mathrm{MC} 1(3.0 \mathrm{mg} / \mathrm{kg})$ and celecoxib $(1.9$ $\mathrm{mg} / \mathrm{kg}$ ) were used as selective COX-2 inhibitors. With ketoprofen, baseline ${ }^{11} \mathrm{C}$-PS13 uptake in the brain, spleen, gastrointestinal tract, and kidneys was blocked up to $86 \%$, whereas the percentage blockade by COX-2 inhibitors was $46 \%$ at most (Table 1 ). Baseline ${ }^{11} \mathrm{C}$-PS13 uptake in other major organs such as the lungs, heart, liver, and testes was also blocked by ketoprofen but was minimally blocked by COX-2 inhibitors. Most organs similarly showed higher blocking effects with aspirin than with COX-2 inhibitors, but the overall difference was less significant than with ketoprofen. Plasma concentrations of ${ }^{11} \mathrm{C}$-PS13 were increased by $14 \%-34 \%$ with administration of COX-1 inhibitors and decreased by $10 \%-19 \%$ with COX-2 inhibitors (Supplemental Fig. 1). Accordingly, the blocking effects of aspirin and celecoxib tended to be slightly underestimated and overestimated, respectively, without correction by plasma concentrations; however, the blocking effects of ketoprofen and MC1 remained almost unchanged.

\section{COX-2 Radioligand: ${ }^{11} \mathrm{C}-\mathrm{MC} 1$}

Whole-Body Biodistribution and Specific Binding. Unlike ${ }^{11} \mathrm{C}-$ PS13, the highest uptake for ${ }^{11} \mathrm{C}-\mathrm{MC} 1$ was observed in excretory organs (gallbladder, liver, urinary bladder), and the uptake was not blocked by MC1 (Fig. 3). In other major organs such as brain, gastrointestinal tract, and spleen, baseline uptake was lower, and the percentage blockade by MC1 was not higher than that obtained by PS13, a COX-1 inhibitor (Table 2). A significant blocking effect by MC1 was observed only in the ovaries compared with the effect of PS13, although baseline ${ }^{11} \mathrm{C}-\mathrm{MC} 1$ uptake in the ovaries was not significantly higher than in other major organs (Fig. 4 and Table 2). The medulla of the kidney also showed a relatively higher percentage blockade by MC1 than by COX-1 inhibitors, but the difference was not conclusive. Because the plasma concentrations of ${ }^{11} \mathrm{C}$ MC1 did not change after MC1 administration (Supplemental Fig. 2), percentage blockade in most organs-including the ovaries and kidneys-remained constant regardless of whether uptake values were corrected by plasma concentrations.

Selective Binding to $\mathrm{COX}-2$. To evaluate the selective binding of ${ }^{11} \mathrm{C}-\mathrm{MC} 1$ to $\mathrm{COX}-2$, celecoxib $(1.2 \mathrm{mg} / \mathrm{kg})$ was used as a selective COX-2 inhibitor, and PS13 (3.0 mg/kg) and aspirin $(22.2 \mathrm{mg} / \mathrm{kg})$ were used as a selective and a preferential COX-1 inhibitor, respectively. Except for the ovaries and perhaps the kidneys, no organ showed a higher percentage blockade by celecoxib than by PS13 or aspirin. Because the plasma concentrations of ${ }^{11} \mathrm{C}$-MC1 were increased by $28 \%$ with administration of PS13 and by 19\% with celecoxib (Supplemental Fig. 2), percentage blockade in most organs was slightly underestimated with PS13 or celecoxib before plasma concentration correction. However, in the ovaries, percentage blockade with celecoxib was higher $(37 \%)$ than with COX-1 inhibitors (0\%-12\%), even before plasma concentration correction.

\section{DISCUSSION}

This study sought to determine whether ${ }^{11} \mathrm{C}-\mathrm{PS} 13$ and ${ }^{11} \mathrm{C}-\mathrm{MC} 1$ could be used to image constitutive levels of COX-1 and COX-2, respectively, in rhesus monkeys. ${ }^{11} \mathrm{C}-\mathrm{PS} 13$ showed significant uptake in expected organs, such as the brain, spleen, gastrointestinal tract, and kidneys, and this uptake was blocked by COX-1, but not by $\mathrm{COX}-2$, inhibitors. In contrast, ${ }^{11} \mathrm{C}-\mathrm{MC} 1$ had minimal specific uptake in major organs other than the ovaries (and perhaps kidneys), though this uptake did show in vivo selectivity for COX-2 over COX-1. Because both radioligands have almost equivalent potency (half-maximal inhibitory concentration, $1 \mathrm{nM}$ ) to their cognate enzymes, we suspect that the constitutive density of COX-2 is lower than that of COX-1. That is, the density of COX-2 may be too low to be detected with a radioligand of only $1 \mathrm{nM}$ potency.

The present study found that constitutive expression of COX-1 in most major organs was reproduced in vivo in a way that had been observed in previous ex vivo studies. In the gastrointestinal tract, high ${ }^{11} \mathrm{C}-\mathrm{PS} 13$ uptake observed under baseline conditions was significantly blocked by COX-1 inhibitors but not by COX-2 inhibitors. Studies have shown that the predominant function of 
TABLE 1

${ }^{11}$ C-PS13 Uptake in Monkey Organs and Percentage Blockade with Pharmacologic Doses of COX-1 and COX-2 Inhibitors

\begin{tabular}{|c|c|c|c|c|c|c|}
\hline \multirow[b]{3}{*}{ Organ } & \multirow[b]{3}{*}{$\operatorname{SUV}_{10-90} \min (n=16)$} & \multicolumn{5}{|c|}{ Blockade (\%) } \\
\hline & & \multicolumn{3}{|c|}{ COX-1 } & \multicolumn{2}{|c|}{ COX-2 } \\
\hline & & PS13 $(n=2)$ & Ketoprofen $^{\dagger}(n=1)$ & Aspirin $(n=2)$ & $\operatorname{MC1}(n=1)$ & Celecoxib $(n=1)$ \\
\hline Brain & $1.88 \pm 0.38$ & $31-49$ & 35 & $23-31$ & 0 & 8 \\
\hline Lungs & $0.50 \pm 0.19$ & $59-68$ & 74 & $27-58$ & 15 & 31 \\
\hline Heart & $1.28 \pm 0.19$ & $20-36$ & 25 & $23-38$ & 10 & 5 \\
\hline Liver & $5.11 \pm 0.79$ & $0-12$ & 24 & $23-29$ & 2 & 1 \\
\hline Spleen & $8.58 \pm 2.91$ & $91-92$ & 86 & $41-58$ & 30 & 46 \\
\hline Gastrointestinal tract & $2.47 \pm 0.56$ & $60-63$ & 61 & $42-52$ & 6 & 0 \\
\hline Kidney cortex & $2.90 \pm 0.57$ & $25-63$ & 69 & $34-47$ & 0 & 0 \\
\hline Kidney medulla & $6.54 \pm 1.42$ & $68-81$ & 78 & $40-44$ & 5 & 11 \\
\hline Ovaries & $1.00 \pm 0.06$ & - & - & 29 & - & - \\
\hline Testes & $1.25 \pm 0.10$ & - & 26 & 23 & - & 0 \\
\hline
\end{tabular}

${ }^{*}$ Corrected by plasma parent radioactivity at 4 timepoints.

${ }^{\dagger}$ Percentage blockade was calculated by SUV $\mathrm{SO}_{10}-70 \mathrm{~min}$ instead of SUV $10-90$ min for 3 plasma data timepoints only in this condition.

COX-1 involves maintaining the integrity of the gastrointestinal mucosa under physiologic conditions and, relatedly, that the adverse effects on the gastrointestinal tract associated with nonselective NSAIDs compared with selective COX-2 inhibitors are mainly due to their inhibitory effect on COX-1 $(19,20)$. The brain similarly showed high ${ }^{11} \mathrm{C}-\mathrm{PS} 13$ uptake that was selective for COX-1. COX-1 is predominantly localized in microglia in the brain and, interestingly, one of the unique characteristics of microglia is that they interact directly with neuronal synapses and survey their microenvironment using highly dynamic processes even under physiologic conditions $(21,22)$. Because microglia have been hypothesized to play a key role in the pathophysiology of neurodegenerative disorders such as Alzheimer disease $(21,23),{ }^{11} \mathrm{C}$-PS13 could be developed as a novel neuroinflammatory biomarker for investigating the mechanisms underlying such disorders and their treatment. ${ }^{11} \mathrm{C}$ PS13 binding in the kidneys, lungs, heart, testes, and ovaries also showed high selectivity to COX-1. These organs are also known to express COX-1 under physiologic conditions, especially in interstitial and supportive cells as well as blood vessels (24).

In contrast, the high and displaceable uptake of ${ }^{11} \mathrm{C}-\mathrm{PS} 13$ in spleen was unexpected, given that previous postmortem studies have noted that levels of COX-1 messenger RNA in the spleen are not higher than in other major organs such as the liver and the kidneys (25). Immunohistochemical staining of the spleen revealed that COX-1 was sparsely localized in scattered cells in red and white pulp, as well as in blood vessels (24). In the present study, the unexpectedly high COX-1 levels observed in vivo may have been caused by the different circulatory status of the spleen between in vivo and ex vivo conditions. Specifically, in the ex vivo spleen, a significant amount of blood cells is washed out during preparation before undergoing immunohistochemical staining or RNA extraction, but those blood cells remain in the spleen during PET scans. The spleen comprises large numbers of sinusoids that physiologically encompass stagnant blood cells, and these cells-particularly platelets-have high constitutive COX-1 activity $(26,27)$.
A critical role for constitutively expressed COX-2 in maintaining physiologic functions has also been suggested in major organs such as the brain, kidneys, ovaries, and gastrointestinal tract (2831). The present study observed clear constitutive expression of COX-2 only in the ovaries and possibly in the kidneys. The ovaries are generally known to have high COX-2 activity given that prostaglandin $\mathrm{E}_{2}$, derived from COX-2, is essential for ovulation (32). As supporting evidence, COX-2 inhibition in female monkeys by meloxicam, a preferential COX-2 inhibitor, prevented pregnancy (33). Furthermore, in the postmortem human ovary, COX-2 was mainly localized in cells of the periovulatory follicle, such as

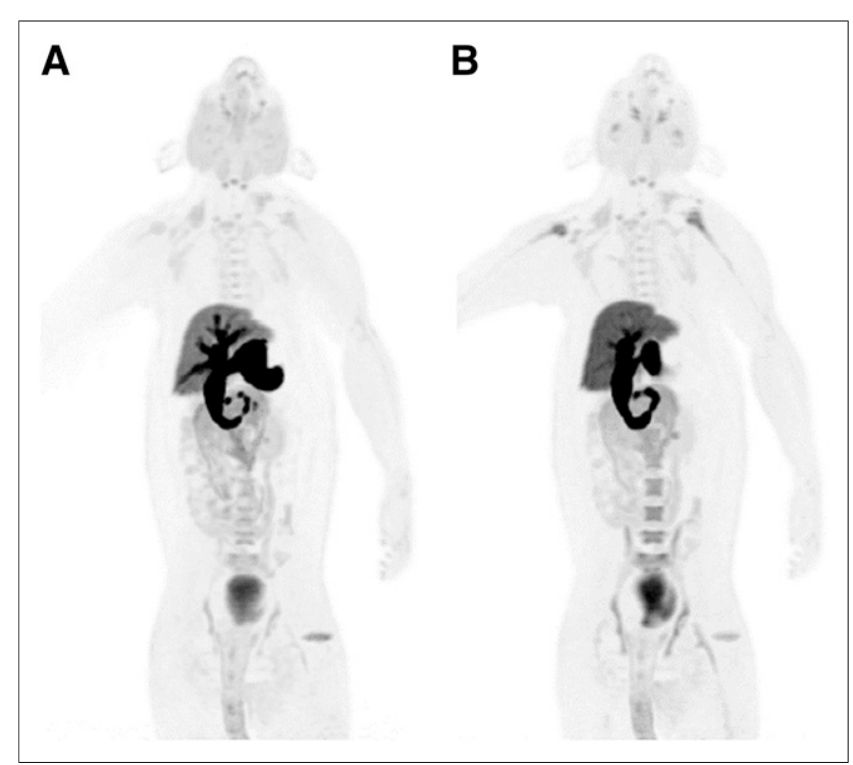

FIGURE 3. Maximum-intensity projections after injection of ${ }^{11} \mathrm{C}-\mathrm{MC} 1$ under baseline conditions (A) and after injection of MC1 $(0.3 \mathrm{mg} / \mathrm{kg})(B)$. High uptake was observed only in excretory organs at baseline and was not blocked by pharmacologic dose of MC1. 
TABLE 2

${ }^{11} \mathrm{C}-\mathrm{MC} 1$ Uptake in Monkey Organs and Percentage Blockade with Pharmacologic Doses of COX-1 and COX-2 Inhibitors

\begin{tabular}{|c|c|c|c|c|c|}
\hline \multirow[b]{3}{*}{ Organ } & \multirow[b]{3}{*}{$\mathrm{SUV}_{10-90 \min }(n=8)$} & \multicolumn{4}{|c|}{ Blockade $(\%)^{*}$} \\
\hline & & \multicolumn{2}{|c|}{$\operatorname{cox}-1$} & \multicolumn{2}{|c|}{ cox-2 } \\
\hline & & $\operatorname{PS} 13(n=1)$ & Aspirin $(n=1)$ & $\operatorname{MC1}(n=1)$ & Celecoxib $(n=1)$ \\
\hline Brain & $1.22 \pm 0.25$ & 17 & 0 & 21 & 0 \\
\hline Lungs & $0.22 \pm 0.05$ & 7 & 0 & 0 & 0 \\
\hline Heart & $0.70 \pm 0.11$ & 7 & 0 & 0 & 0 \\
\hline Liver & $9.10 \pm 2.42$ & 21 & 0 & 0 & 14 \\
\hline Spleen & $0.63 \pm 0.10$ & 12 & 0 & 0 & 5 \\
\hline Gastrointestinal tract & $1.10 \pm 0.26$ & 19 & 0 & 14 & 0 \\
\hline Kidney cortex & $1.73 \pm 0.36$ & 16 & 5 & 16 & 22 \\
\hline Kidney medulla & $1.91 \pm 0.27$ & 22 & 13 & 35 & 30 \\
\hline Ovaries & $0.82 \pm 0.23$ & 12 & 12 & 38 & 46 \\
\hline
\end{tabular}

${ }^{*}$ Corrected by plasma parent radioactivity at 4 timepoints.

oocytes, theca cells, and granulosa cells, whereas COX-1 was more localized in supporting cells such as surface epithelium and stromal cells (24). Likewise, COX-2 in the kidney is thought to play an even more critical role than COX-1 in maintaining physiologic renal functions $(34,35)$. It has also been suggested that renal and cardiovascular side effects observed during recent clinical trials with NSAIDs are significantly linked to inhibition of constitutive COX-2 activity in the kidney $(36,37)$.

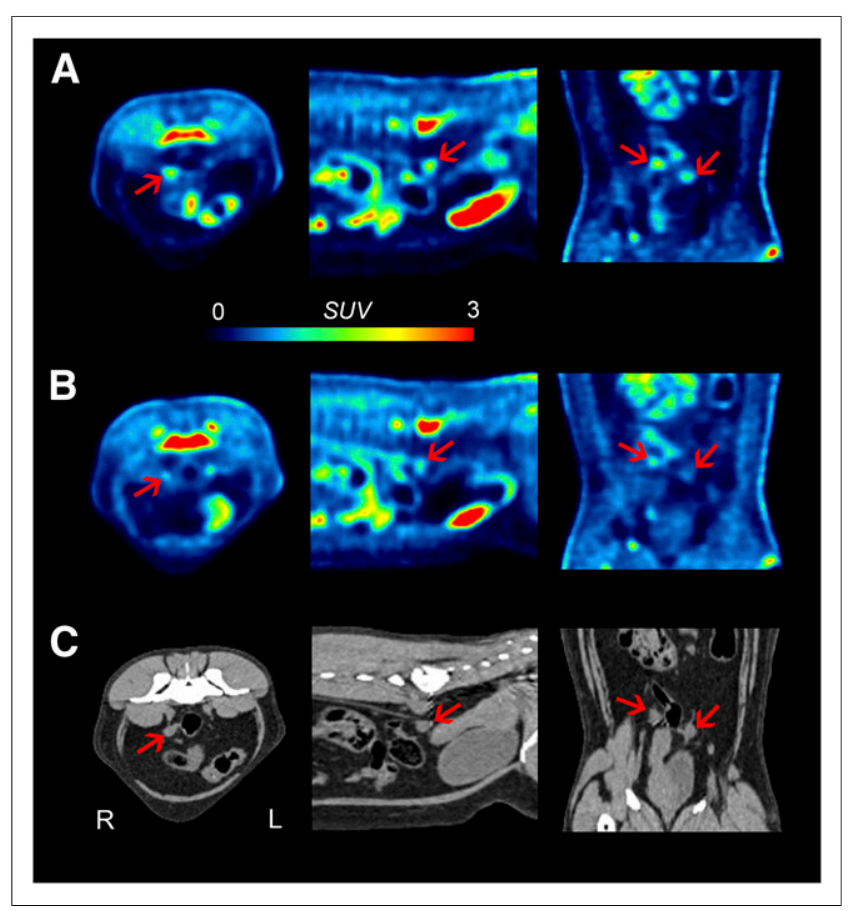

FIGURE 4. Whole-body PET images after injection of ${ }^{11} \mathrm{C}-\mathrm{MC} 1 \mathrm{under}$ baseline conditions (A) and after injection of $\mathrm{MC1}(0.3 \mathrm{mg} / \mathrm{kg})(B)$, as well as corresponding CT images (C). High uptake was observed in both ovaries (arrows) and was blocked by pharmacologic dose of MC1, consistent with specific binding to COX-2. PET images are shown as SUV.
It remains unclear why, in the present study, ${ }^{11} \mathrm{C}-\mathrm{MC} 1$ lacked the sensitivity needed to detect the relatively widespread distribution of COX-2 in healthy animals. Two likely possibilities are low specific signal and high nonspecific signal. Specific binding is proportional to the affinity of the radioligand. Although the affinity of MC1 is high in absolute terms, it may be inadequate relative to the presumably low levels of COX-2 in the basal state. To the best of our knowledge, no reports exist of the absolute density of COX-2 in organs of the body. Nonspecific uptake is correlated with lipophilicity, and $\mathrm{MC} 1$ is relatively lipophilic $(\operatorname{mlog} D=3.74)$. Because the brain has a high lipid content, and because the gastrointestinal tracts are surrounded by abundant fat tissues, the radioligand may have a high amount of nonspecific-compared with specific-binding to COX-2, resulting in low sensitivity for imaging COX-2.

Finally, it is also difficult to interpret the finding that substantial uptake of ${ }^{11} \mathrm{C}$-PS13 in the spleen as well as lungs and heart was also reduced by selective $\mathrm{COX}-2$ inhibitors, and that ${ }^{11} \mathrm{C}-\mathrm{MC} 1$ uptake in a few organs was blocked by PS13, a highly selective COX-1 inhibitor. One possibility is that the dose or actual bioavailability of the drugs we used as preblockers was high enough to not only inhibit the intended COX isoform but also inhibit the other isoform. Polyethylene glycol 400 (PEG 400), which was used as an excipient in formulating the PS13, MC1, and celecoxib solutions, may have also enhanced the bioavailability of drugs by either decreasing renal elimination (38) or increasing plasma free fraction, as demonstrated in our in vitro experiment (Supplemental Fig. 3). Indeed, intravenous administration of celecoxib formulated with PEG 400 has resulted in 4-fold increased bioavailability compared with oral administration (39). Other possible factors include noise in the PET images, contamination by radiometabolites, and confounding by stagnant blood cells, all of which might have interfered with our ability to accurately measure blocking effects in particular organs.

\section{CONCLUSION}

This study sought to assess the potential utility of ${ }^{11} \mathrm{C}-\mathrm{PS} 13$ and ${ }^{11} \mathrm{C}-\mathrm{MC} 1$ as tools for measuring inflammation in various disorders as well as target engagement by NSAIDs. Using these novel radioligands, constitutive expression of COX-1 was observed in major 
organs while that of COX-2 was minimal in rhesus monkeys. ${ }^{11} \mathrm{C}$ PS13 was found to have adequate signal in monkeys to justify its extension to healthy human subjects. In contrast, ${ }^{11} \mathrm{C}-\mathrm{MC} 1$ is unlikely to show significant signal in healthy humans but may be able to do so in inflammatory conditions marked by significant upregulation of COX-2, such as autoimmune and neoplastic disorders.

\section{DISCLOSURE}

This study was funded by the Intramural Research Program of the National Institute of Mental Health, National Institutes of Health: projects ZIAMH002795 and ZIAMH002793. No other potential conflict of interest relevant to this article was reported.

\section{ACKNOWLEDGMENTS}

We thank Dr. Krystal Allen-Worthington, Ms. Johnetta Gray, Mr. James Michael Fellows, and Mr. Tywan Lewis for animal care and support; to the NIH PET department for technical support; and to Ioline Henter (NIMH) for providing invaluable editorial assistance.

\section{REFERENCES}

1. Smith WL, Garavito RM, DeWitt DL. Prostaglandin endoperoxide H synthases (cyclooxygenases)-1 and -2. J Biol Chem. 1996;271:33157-33160.

2. Crofford LJ, Wilder RL, Ristimaki AP, et al. Cyclooxygenase-1 and -2 expression in rheumatoid synovial tissues: effects of interleukin-1 beta, phorbol ester, and corticosteroids. J Clin Invest. 1994;93:1095-1101.

3. Giuliano F, Warner TD. Ex vivo assay to determine the cyclooxygenase selectivity of non-steroidal anti-inflammatory drugs. Br J Pharmacol. 1999;126:1824-1830.

4. Aisen PS, Thal LJ, Ferris SH, et al. Rofecoxib in patients with mild cognitive impairment: further analyses of data from a randomized, double-blind, trial. Curr Alzheimer Res. 2008;5:73-82.

5. Martin BK, Szekely C, Brandt J, et al. Cognitive function over time in the Alzheimer's Disease Anti-inflammatory Prevention Trial (ADAPT): results of a randomized, controlled trial of naproxen and celecoxib. Arch Neurol. 2008;65: 896-905.

6. ADAPT-FS Research Group. Follow-up evaluation of cognitive function in the randomized Alzheimer's Disease Anti-inflammatory Prevention Trial and its follow-up study. Alzheimers Dement. 2015;11:216-225.e1.

7. Dembo G, Park SB, Kharasch ED. Central nervous system concentrations of cyclooxygenase-2 inhibitors in humans. Anesthesiology. 2005;102:409-415.

8. Shukuri M, Takashima-Hirano M, Tokuda K, et al. In vivo expression of cyclooxygenase-1 in activated microglia and macrophages during neuroinflammation visualized by PET with ${ }^{11} \mathrm{C}$-ketoprofen methyl ester. J Nucl Med. 2011;52:1094-1101.

9. Shukuri M, Mawatari A, Ohno M, et al. Detection of cyclooxygenase-1 in activated microglia during amyloid plaque progression: PET studies in Alzheimer's disease model mice. J Nucl Med. 2016;57:291-296.

10. Ohnishi A, Senda M, Yamane T, et al. Exploratory human PET study of the effectiveness of ${ }^{11} \mathrm{C}$-ketoprofen methyl ester, a potential biomarker of neuroinflammatory processes in Alzheimer's disease. Nucl Med Biol. 2016;43:438-444.

11. Tietz O, Wuest M, Marshall A, et al. PET imaging of cyclooxygenase-2 (COX-2) in a pre-clinical colorectal cancer model. EJNMMI Res. 2016;6:37.

12. Uddin MJ, Crews BC, Ghebreselasie K, et al. Fluorinated COX-2 inhibitors as agents in PET imaging of inflammation and cancer. Cancer Prev Res (Phila). 2011;4:1536-1545.

13. Ji B, Kumata K, Onoe H, et al. Assessment of radioligands for PET imaging of cyclooxygenase-2 in an ischemic neuronal injury model. Brain Res. 2013;1533: $152-162$.

14. Cortes M, Singh P, Morse C, et al. Synthesis of PET radioligands as potential probes for imaging COX-2 in neuroinflammation [abstract]. J Nucl Med. 2015;56 (suppl): 1092 .

15. Singh P, Shrestha S, Cortes-Salva MY, et al. 3-substituted 1,5-diaryl- ${ }^{1} \mathrm{H}-1,2,4-$ triazoles as prospective PET radioligands for imaging brain COX-1 in monkey. Part 1: synthesis and pharmacology. ACS Chem Neurosci. June 13, 2018 [Epub ahead of print].
16. Shrestha S, Singh P, Cortes-Salva MY, et al. 3-Substituted 1,5-diaryl-1 H-1,2,4triazoles as prospective PET radioligands for imaging brain COX-1 in monkey. Part 2: selection and evaluation of $\left[{ }^{11} \mathrm{C}\right] \mathrm{PS} 13$ for quantitative imaging. ACS Chem Neurosci. June 13, 2018 [Epub ahead of print].

17. Institute for Laboratory Animal Research in National Research Council. Guide for the Care and Use of Laboratory Animals. 8th ed. Washington, DC: National Academies Press; 2011:1-202.

18. Zoghbi SS, Shetty HU, Ichise M, et al. PET imaging of the dopamine transporter with ${ }^{18} \mathrm{~F}$-FECNT: a polar radiometabolite confounds brain radioligand measurements. J Nucl Med. 2006;47:520-527.

19. Tsuji S, Miyoshi H, Tomita T, et al. Celecoxib, a cyclooxygenase-2 inhibitor, improved upper gastrointestinal lesions in rheumatoid arthritis patients as assessed by endoscopic evaluation. Mod Rheumatol. 2012;22:353-362.

20. Takeuchi K, Tanaka A, Kato S, Amagase K, Satoh H. Roles of COX inhibition in pathogenesis of NSAID-induced small intestinal damage. Clin Chim Acta. 2010;411:459-466.

21. Yermakova AV, Rollins J, Callahan LM, Rogers J, O'Banion MK. Cyclooxygenase-1 in human Alzheimer and control brain: quantitative analysis of expression by microglia and CA3 hippocampal neurons. J Neuropathol Exp Neurol. 1999;58: 1135-1146.

22. Michell-Robinson MA, Touil H, Healy LM, et al. Roles of microglia in brain development, tissue maintenance and repair. Brain. 2015;138:1138-1159.

23. Arends YM, Duyckaerts C, Rozemuller JM, Eikelenboom P, Hauw JJ. Microglia, amyloid and dementia in Alzheimer disease: a correlative study. Neurobiol Aging. 2000;21:39-47.

24. Zidar N, Odar K, Glavac D, Jerse M, Zupanc T, Stajer D. Cyclooxygenase in normal human tissues: is COX-1 really a constitutive isoform, and COX-2 an inducible isoform? J Cell Mol Med. 2009;13:3753-3763.

25. Yasojima K, Schwab C, McGeer EG, McGeer PL. Distribution of cyclooxygenase- 1 and cyclooxygenase-2 mRNAs and proteins in human brain and peripheral organs. Brain Res. 1999;830:226-236.

26. Belton O, Byrne D, Kearney D, Leahy A, Fitzgerald DJ. Cyclooxygenase-1 and -2-dependent prostacyclin formation in patients with atherosclerosis. Circulation. 2000;102:840-845.

27. Rocca B, Secchiero P, Celeghini C, et al. Modulation of the expression and activity of cyclooxygenases in normal and accelerated erythropoiesis. Exp $\mathrm{He}$ matol. 2004;32:925-934.

28. Simmons DL, Botting RM, Hla T. Cyclooxygenase isozymes: the biology of prostaglandin synthesis and inhibition. Pharmacol Rev. 2004;56:387-437.

29. Weerasinghe GR, Coon SL, Bhattacharjee AK, Harry GJ, Bosetti F. Regional protein levels of cytosolic phospholipase A2 and cyclooxygenase-2 in Rhesus monkey brain as a function of age. Brain Res Bull. 2006;69:614-621.

30. Wallace JL, McKnight W, Reuter BK, Vergnolle N. NSAID-induced gastric damage in rats: requirement for inhibition of both cyclooxygenase 1 and 2 . Gastroenterology. 2000;119:706-714.

31. Kaufmann WE, Worley PF, Pegg J, Bremer M, Isakson P. COX-2, a synaptically induced enzyme, is expressed by excitatory neurons at postsynaptic sites in rat cerebral cortex. Proc Natl Acad Sci USA. 1996;93:2317-2321.

32. Matsumoto H, Ma W, Smalley W, Trzaskos J, Breyer RM, Dey SK. Diversification of cyclooxygenase-2-derived prostaglandins in ovulation and implantation. Biol Reprod. 2001;64:1557-1565.

33. McCann NC, Lynch TJ, Kim SO, Duffy DM. The COX-2 inhibitor meloxicam prevents pregnancy when administered as an emergency contraceptive to nonhuman primates. Contraception. 2013;88:744-748.

34. Morham SG, Langenbach R, Loftin CD, et al. Prostaglandin synthase 2 gene disruption causes severe renal pathology in the mouse. Cell. 1995;83:473-482.

35. Langenbach R, Morham SG, Tiano HF, et al. Prostaglandin synthase 1 gene disruption in mice reduces arachidonic acid-induced inflammation and indomethacin-induced gastric ulceration. Cell. 1995;83:483-492.

36. Kirkby NS, Chan MV, Zaiss AK, et al. Systematic study of constitutive cyclooxygenase-2 expression: role of NF-kappaB and NFAT transcriptional pathways. Proc Natl Acad Sci USA. 2016;113:434-439.

37. Ahmetaj-Shala B, Kirkby NS, Knowles R, et al. Evidence that links loss of cyclooxygenase- 2 with increased asymmetric dimethylarginine: novel explanation of cardiovascular side effects associated with anti-inflammatory drugs. Circulation. 2015;131:633-642.

38. Buggins TR, Dickinson PA, Taylor G. The effects of pharmaceutical excipients on drug disposition. Adv Drug Deliv Rev. 2007;59:1482-1503.

39. Paulson SK, Vaughn MB, Jessen SM, et al. Pharmacokinetics of celecoxib after oral administration in dogs and humans: effect of food and site of absorption. $J$ Pharmacol Exp Ther. 2001;297:638-645. 